\title{
CZECH CAPITAL MARKET WEAK-FORM EFFICIENCY, SELECTED ISSUES
}

\author{
Jan Hájek*
}

\begin{abstract}
:
The article discusses several factors that should be addressed when analysing linear dependences and testing the Efficient Market Hypothesis on the Czech capital market in order to avoid possible interpretation biases. The conclusions are based on the empirical analysis of the stock return behaviour in 1995-2005 and the generalization of the up-to-date local studies outcomes. It also discusses the market's relative efficiency compared to capital markets that are considered the most effective worldwide and on the European territory - the American NYSE and the German and Netherlands stock exchanges. Significant linear dependences of daily returns are typical on the Czech capital market; its relative efficiency still lags behind the efficiency of the developed markets.
\end{abstract}

Keywords: Efficient Market Hypothesis, weak-form efficiency, relative efficiency, random walk, variance ratio test, conditional heteroskedasticity, non-synchronous trading, data frequency, Czech stock market

JEL Classification: G14, C22

\section{Introduction}

A number of studies have addressed the Efficient Market Hypothesis (EMH) in Central Europe in the last decade. Nevertheless, the hypothesis has not been tested with respect to the extent and complexity that is typical for developed markets, also due to the rather short history of the markets. Moreover, the studies have often delivered rather ambiguous conclusions subject to various approaches, analysed data sets and technical aspects. The article addresses the efficient stock market hypothesis in the Czech Republic in 1995-2005. Based on the empirical analysis and available studies, major factors that may influence the results are analysed and, if meaningful, generalized. The article helps to interpret several sources of discrepancies in the up-to-now studies and it aims to contribute to better understanding of the Czech stock market behaviour in terms of the weak-form efficiency hypothesis.

* jan.hajek@dexia-kom.cz 
The Efficient Market Hypothesis - specifically its weak, semi-strong or strong form ${ }^{1}$ - is traditionally related to investor's opportunity to reach abnormal profits in the long term using a specific form of the stock behaviour analysis. Should the time series of stock (or index) returns be dependent and the dependences are economically significant, the analysed market is inefficient in terms of the weak form of the EMH. An investor may employ technical analysis tools to identify an investment strategy that exploits the stock return predictability and is abnormally profitable. Should the market reach the weak-form efficiency but fails to be semi-strong efficient, i.e. prices incorrectly reflect all public information, fundamental analysis may be used to investigate departures of stock prices from the fair values. Otherwise, investors may be abnormally profitable in the long term (but not necessarily) only when employing insider information; both technical and fundamental analysis then fails to deliver above-average profits.

A simple test of linear dependences is applied in the empirical part of the article. The results are then compared to the outcomes of the available studies. Major factors that may have significant impact on the result interpretation are analysed; the non-trading effect, sufficient time span, data frequency and relative efficiency are addressed to avoid possible biases. The relative efficiency test compares the frequency of significant dependences on the Czech market and developed markets (markets that are considered the most effective worldwide). The approach implicitly allows for reflecting transaction costs as far as they have similar size and impact on both markets. The relative efficiency test delivers additional information and improves robustness of the results even if the size and impact differ, though. Several generalized conclusions are finally suggested.

\section{Data}

Time series of the PX-50 and PX-D index closing values and stock closing prices on the Prague Stock Exchange are analysed. ${ }^{2}$ Appendix 1 provides an overview of the analysed stocks. The analysed period begins in January 1995 as the PSE introduced the daily trading only in 1994. Time series ends in December 2005, unless a stock has been delisted earlier. Considering the EMH assumptions, the eleven-year time span seems sufficient to obtain rather robust results. The data source is Bloomberg.

Empirical tests are applied to monthly, weekly and daily data. The analysis may thus detect systemic (predictable) return behaviour with respect to different time horizons. If any stock began to be listed later than in 1995, time series of monthly returns would be insufficiently long and it has been excluded from the analysis. Weekly returns are calculated using all weekdays as the return decisive day so that five sets of time series and results are obtained. Non-trading weekdays (holidays, etc.) are left in the time series and their influence is addressed in the detailed non-synchronous trading analysis. Time series of split stocks are recalculated backwards to their new nominal values.

In order to test relative efficiency of the Czech capital market, time series of stock returns on the most developed markets are also analysed. Specifically, members of the

1 The core principles of the Efficient Market Hypothesis have been formulated by Fama $(1965,1970)$ and Samuelson (1965). The three-form classification has been introduced by Roberts (1967).

2 Note that the PX-50 and PX-D indices merged into the PX index in 2006. 
major global and European indices - Dow Jones Industrial Average, DAX and AEX, respectively - constitute the benchmark.

\section{Empirical Analysis}

Several factors that may have significant impact on the outcomes of the linear dependences analysis and the EMH test are addressed in the following five subchapters. The effects of heteroskedasticity, non-trading, sufficient time span, data frequency and relative efficiency are empirically analysed in the context of the Czech market. The methodology is described at the beginning of each respective subchapter in contrast to the traditional explanation in a separate chapter. This approach has been chosen to easily follow the analysis that comprises of several specific parts.

\subsection{Conditional Heteroskedasticity}

Autoregression Conditional Heteroskedasticity and its implications for the EHM testing are widely recognized. The original random-walk assumption of the identically distributed returns is very restrictive and numerous empirical studies have proved that stock returns are conditional heteroskedastical. Heteroskedasticity increases the empirical level of confidence, i.e. the probability of the first order error, above the "standard" level under the assumption of the constant variance. Unadjusted methodology may lead (and usually does) to an unjustifiable refusal of the null hypothesis of the stock-return independence. In the article, the hereroskedasticity-consistent variance-ratio test is applied according to the methodology of Lo, Mackinlay $(1988,1989)$. Their adjustments ensure that in case of uncorrelated returns the variance ratio asymptotically approaches unity even if the variance is time-variable. Modified test statistic $\psi^{*}(q)$ satisfies many forms of variable volatility including seasonal changes in the variance or Engle's ARCH process ${ }^{3}$ :

$$
\psi *(q)=\sqrt{n q}(\overline{V R}(q)-1) / \sqrt{\hat{\theta}(q)}
$$

The statistic has asymptotically $\mathrm{N}(0,1)$ distribution, while the estimated asymptotical variance $\theta(q)$ of the estimated variance ratio $\overline{V R}(q)$ is given:

$$
\hat{\theta}(q)=4 \sum_{k=1}^{q-1}\left(1-\frac{k}{q}\right)^{2} \hat{\delta}_{k}
$$

where $\hat{\delta}_{k}$ are the estimated asymptotic variances of the estimated autocorrelation coefficients $\hat{\rho}_{k}$, which may be written:

$\left.\hat{\delta}_{k}=n q \sum_{j=k+1}^{n q}\left(p_{j} p_{j-1}-\hat{\mu}\right)^{2}\left(p_{j-k}-p_{j-k-1}-\hat{\mu}\right)^{2} /\left[\sum_{j=1}^{n q} p_{j}-p_{j-1}-\hat{\mu}\right)^{2}\right]^{2}$

3 See Engle (1982). 
It holds in general:

$$
V R(q)=\frac{\sigma^{2}\left[r_{t}(q)\right]}{q \sigma^{2}\left[r_{t}\right]}=1+2 \sum_{k=1}^{q-1}\left(1-\frac{k}{q}\right) \cdot \rho_{k}
$$

where $k$ expresses a number of legs and where $q$ is number of returns included in the shorter period $\left(r_{t}(q)=r_{t}+r_{t-1}+\ldots+r_{t-q+1}\right)$.

The estimated variance ratio $\overline{V R}(q)$ of time series with $n q+1$ observations equals:

$$
\overline{V R}(q)=\frac{\bar{\sigma}_{c}^{2}(q)}{\bar{\sigma}_{a}^{2}}
$$

where $\bar{\sigma}_{a}^{2}=\frac{1}{n q-1} \sum_{k=q}^{n q}\left(p_{k}-p_{k-1}-\hat{\mu}\right)^{2}$ and

$\bar{\sigma}_{c}^{2}(q)=\frac{1}{q(n q-q+1)(1-q / n q)} \sum_{k=q}^{n q}\left(p_{k}-p_{k-q}-q \hat{\mu}\right)^{2}$

while $\hat{\mu}$ is the estimated mean of time series.

The impact of heteroskedasticity and the importance of appropriate methodology adjustments are demonstrated below. If the variance ratio test is applied on the Czech stock market under the homoskedasticity assumption only two time series of individual stocks are linearly independent (for $q=2$ ), whereas a third of time series satisfies the random walk in the case of the time-varying variance, as shown in Table 1.

Table 1

Variance Ratio Test (q=2), CZ, Daily Returns, 1995-2005, Heteroskedasticity

\begin{tabular}{|l|c|c|l|c|c|l|c|c|}
\hline & $\begin{array}{c}\text { Test } \\
\text { statistic } \\
\mathbf{Z}_{\mathbf{2}^{*}}\end{array}$ & $\begin{array}{c}\mathbf{N}(\mathbf{0 , 1}) \\
\text { 2-sided } \\
\text { probability }\end{array}$ & & $\begin{array}{c}\text { Test } \\
\text { statistic } \\
\mathbf{Z}_{\mathbf{2}^{*}}\end{array}$ & $\begin{array}{c}\mathbf{N}(\mathbf{0 , 1}) \\
\text { 2-sided } \\
\text { probability }\end{array}$ & & $\begin{array}{c}\text { Test } \\
\text { statistic } \\
\mathbf{Z}_{\mathbf{2}^{*}}\end{array}$ & $\begin{array}{c}\mathbf{N}(\mathbf{0 , 1}) \\
\text { 2-sided } \\
\text { probability }\end{array}$ \\
\hline CBJ & 2.90349 & 0.00369 & OKD & 8.28297 & 0.00000 & SVEG & 5.16252 & 0.00000 \\
\hline CEZ & 2.55289 & 0.01068 & PARM & 5.49858 & 0.00000 & SVEN & 3.43990 & 0.00058 \\
\hline CS & 1.64577 & 0.09981 & RBAG & 1.42225 & 0.15495 & TABAK & -0.34500 & 0.73010 \\
\hline CSRD & 2.71257 & 0.00668 & SKUH & 4.85084 & 0.00000 & UNIP & 2.77313 & 0.00555 \\
\hline IAPS & 1.40573 & 0.15980 & SPTT & 1.63142 & 0.10280 & & & \\
\hline IPB & 1.74391 & 0.08118 & SSZL & 4.62984 & 0.00000 & PX-50 & 4.49988 & 0.00001 \\
\hline KOMB & 3.50096 & 0.00046 & SVDL & 4.16496 & 0.00003 & PX D & 1.08499 & 0.27793 \\
\hline
\end{tabular}

Based on the above, an importance of the heteroskedasticity-consistent methodology has been highlighted. Filer, Hanousek (1996) have firstly recognized heteroskedasticity on the Czech market in case of the PX-50 index. With sparse exceptions, the 
time-variable character of the return variance has been correctly reflected in empirical studies of the Central-European markets. ${ }^{4}$

\subsection{Time Span}

The EMH claims that a market is efficient as far as a certain information set cannot be used to gain above-average profits in the long term. While significant short-term departures from the "fair" profits are possible, they offset in the long term and the hypothesis holds. Roll (1994), Fama (1997) and Malkiel (2003) allow for random anomalies that do not infringe the core of the EMH. The sufficient length is thus important for the analysed time series to contain information on the structural (systemic) character of the market and ignore interim variations. ${ }^{5}$

Studies of the Central European market efficiency begun to emerge in the second half of the 1990s. Filer, Hanousek (1996) concluded that the Czech, Slovak, Hungarian and Polish equity markets behaved in line with the random walk model and were weak-form efficient. Even more, they claimed that the markets might reach the higher forms of efficiency. Dockery, Vergari (1997) confirmed random behaviour of the Hungarian stock index, BUX. However, short time series led to limited robustness of the presented results, especially with regard to the low-frequency data analysis (i.e. based on weekly or monthly returns). Later studies, which have described developments of the efficiency over time by analysing market characteristics in successive sub-periods, have also suffered from rather low reliability. Recent studies have brought ambiguous and even contradictory outcomes. For example, Worthington, Higgs (2003), Žikeš (2003) or Hájek (2002) concluded that behaviour of the Czech market is non-random and (weak-from) inefficient.

The analysed time series cover the period of 1995-2005. The eleven-year time span seems sufficient to allow robust results. Series are, however, also halved and tested whether an analysis of shorter periods may deliver relevant outcomes. Tables 2 and 3 summarize results for the both sub-periods. While two thirds of the time series of individual stock are significantly linearly dependent between 1995 and 2000, a half of them are autocorrelated in the second sub-period. Not only the number of titles and intensity of the dependences decreased, but the behaviour of both indices is random in 2000-2005. One may have concluded that the Czech market moved closer to efficiency over the analysed period.

However, as mentioned above, it is questionable if the analysis of five-year periods may lead to powerful conclusions. The same sub-periods have been therefore analysed on the NYSE and the results have been compared. The US market is assumed to be the most effective capital market worldwide; no major changes in its character are likely over the short-time span. The analysis of behaviour of 30 blue chips - the constituents of

4 Nivet (1997) has not reflected heteroskedasticity properly in his analysis of the Polish market. Unsurprisingly, the study has identified autocorrelated returns.

5 On the other hand, empirical studies should reflect structural brakes that accompany major socio-political events. For example, WWII represents such an event on the US market and empirical studies brought contradictory outcomes when applied data before and after the break. One may conclude that time series should optimally cover several decades. 
the Dow Jones Industrial Average index - has, however, detected that daily returns of 6 stocks are linearly dependent in 1995-2000 compared to the single exception from the random walk that can be found in the second sub-period.

Table 2

Variance Ratio Test ( $q=2$ ), CZ, Daily Returns, 1995-2000

\begin{tabular}{|l|c|c|l|c|c|l|c|c|}
\hline & $\begin{array}{c}\text { Test } \\
\text { statistic } \\
\mathbf{Z}_{\mathbf{2}^{*}}\end{array}$ & $\begin{array}{c}\mathbf{N}(\mathbf{0 , 1}) \\
\mathbf{2 - s i d e d} \\
\text { probability }\end{array}$ & & $\begin{array}{c}\text { Test } \\
\text { statistic } \\
\mathbf{Z}_{\mathbf{2}^{*}}\end{array}$ & $\begin{array}{c}\mathbf{N}(\mathbf{0 , 1}) \\
\mathbf{2 - s i d e d} \\
\text { probability }\end{array}$ & & $\begin{array}{c}\text { Test } \\
\text { statistic } \\
\mathbf{Z}_{\mathbf{2}^{*}}\end{array}$ & $\begin{array}{c}\mathbf{N}(\mathbf{0 , 1}) \\
\text { 2-sided } \\
\text { probability }\end{array}$ \\
\hline CBJ & 2.55075 & 0.01075 & OKD & 7.56416 & 0.00000 & SVEN & 2.62089 & 0.00877 \\
\hline CEZ & 3.22011 & 0.00128 & PARM & 3.46409 & 0.00053 & TABAK & -0.53713 & 0.59118 \\
\hline CS & 1.61627 & 0.10604 & SKUH & 4.35424 & 0.00001 & UNIP & 1.75806 & 0.07874 \\
\hline CSRD & 2.33129 & 0.01974 & SPTT & 1.90030 & 0.05739 & & & \\
\hline IAPS & 0.91403 & 0.36070 & SSZL & 3.56830 & 0.00036 & PX-50 & 5.02023 & 0.00000 \\
\hline IPB & 1.74391 & 0.08118 & SVDL & 2.38776 & 0.01695 & PX D & 0.96941 & 0.33234 \\
\hline KOMB & 3.23872 & 0.00120 & SVEG & 3.99627 & 0.00006 & & & \\
\hline
\end{tabular}

Table 3

Variance Ratio Test ( $q=2$ ), CZ, Daily Returns, 2000-2005

\begin{tabular}{|l|c|c|l|c|c|l|c|c|}
\hline & $\begin{array}{c}\text { Test } \\
\text { statistic } \\
\mathbf{Z}_{\mathbf{2}^{\star}}\end{array}$ & $\begin{array}{c}\mathbf{N}(\mathbf{0 , 1}) \\
\mathbf{2 - s i d e d} \\
\text { probability }\end{array}$ & & $\begin{array}{c}\text { Test } \\
\text { statistic } \\
\mathbf{Z}_{\mathbf{2}^{\star}}\end{array}$ & $\begin{array}{c}\mathbf{N}(\mathbf{0 , 1}) \\
\mathbf{2 - s i d e d} \\
\text { probability }\end{array}$ & & $\begin{array}{c}\text { Test } \\
\text { statistic } \\
\mathbf{Z}_{\mathbf{2}^{\star}}\end{array}$ & $\begin{array}{c}\mathbf{N}(\mathbf{0 , 1}) \\
\text { 2-sided } \\
\text { probability }\end{array}$ \\
\hline CBJ & 1.34010 & 0.18021 & PARM & 4.42501 & 0.00001 & SVEN & 3.03082 & 0.00244 \\
\hline CEZ & 0.43796 & 0.66142 & RBAG & 1.42225 & 0.15495 & TABAK & 0.12575 & 0.89993 \\
\hline CS & 0.96235 & 0.33587 & SKUH & 1.92950 & 0.05367 & UNIP & 2.10315 & 0.03545 \\
\hline CSRD & 1.40714 & 0.15939 & SPTT & 0.67120 & 0.50209 & & & \\
\hline IAPS & 1.67373 & 0.09418 & SSZL & 2.94095 & 0.00327 & PX-50 & 1.09660 & 0.27282 \\
\hline IPB & 2.00366 & 0.04511 & SVDL & 3.44414 & 0.00057 & PX D & 0.70418 & 0.48132 \\
\hline KOMB & 3.48030 & 0.00050 & SVEG & 4.00355 & 0.00006 & & & \\
\hline
\end{tabular}

Could one claim that NYSE's characteristics have changed significantly and the market has become (weak-form) efficient only in the last several years? A more reliable interpretation would suggest that the analysed time span remains insufficient and limits robustness of the results. No major conclusions may be thus presented regarding changes in the Czech market efficiency, if short-period data is used. To sum up, time series of the maximal available length should be used if the Central European market efficiency is analysed.

\subsection{Data Frequency}

The data frequency is another key factor that may have significant impact on reported conclusions. In general terms, the lower data frequency the higher probability that prices fairly reflect all relevant information. Even on less developed and less liquid markets - including the Central European exchanges - a month period seems sufficient to absorb new information. Analysing daily data may deliver less straightforward 
results, especially compared to the most developed markets. Recall, however, that even daily linear dependences contradict the EMH (once they are economically significant).

Impact of the frequency choice is demonstrated on the Czech market again. As Table 1 shows, time series of the daily stock returns as well as the PX-50 daily returns are usually linearly dependent. The systemic departures from the random walk do not support the EMH. Moreover, most available daily-data studies have concluded that the return behaviour does not support the weak-form efficiency hypothesis on the Czech market as well. ${ }^{6}$ Schotman, Zalewska (2004), the only exception, claim that the market became efficient in 1999 if the methodology allowing for the time-varying parameters is applied.

On the other hand, Table 4 clearly emphasizes that autocorrelations of monthly returns remain only exceptional on the Czech market. ${ }^{7}$ Also Filer, Hanousek (1996 and 1999), Hájek (2002), Gilmore, McManus (2003), Gunduz, Hatemi-J (2005) and Diviš, Teplý (2005) analysed time series of weekly or monthly returns and concluded that the random walk holds there. The prevailing evidence thus supports the weak-form efficiency hypothesis for both individual stocks and market indices, contrary to the daily data analysis. ${ }^{8}$

Table 4

Variance Ratio Test ( $q=2$ ), CZ, Monthly Returns, 1995-2005

\begin{tabular}{|l|c|c|l|c|c|l|c|c|}
\hline & $\begin{array}{c}\text { Test } \\
\text { statistic } \\
\mathbf{Z}_{\mathbf{2}^{*}}\end{array}$ & $\begin{array}{c}\mathbf{N}(\mathbf{0 , 1}) \\
\mathbf{2} \text {-sided } \\
\text { probability }\end{array}$ & & $\begin{array}{c}\text { Test } \\
\text { statistic } \\
\mathbf{Z}_{2^{*}}\end{array}$ & $\begin{array}{c}\mathbf{N}(\mathbf{0 , 1}) \\
\text { 2-sided } \\
\text { probability }\end{array}$ & & $\begin{array}{c}\text { Test } \\
\text { statistic } \\
\mathbf{Z}_{2^{*}}\end{array}$ & $\begin{array}{c}\mathbf{N}(\mathbf{0 , 1}) \\
\text { 2-sided } \\
\text { probability }\end{array}$ \\
\hline CBJ & 0.61063 & 0.54144 & OKD & 1.11296 & 0.26573 & SVEG & -0.23761 & 0.81218 \\
\hline CEZ & 0.06769 & 0.94604 & PARM & 0.71056 & 0.47735 & SVEN & 0.00683 & 0.99455 \\
\hline CS & 0.93469 & 0.34995 & RBAG & -1.14635 & 0.25165 & TABAK & 0.43767 & 0.66162 \\
\hline CSRD & 1.12547 & 0.26039 & SKUH & 1.32807 & 0.18415 & UNIP & 0.86488 & 0.38711 \\
\hline IAPS & 2.15728 & 0.03098 & SPTT & -1.05413 & 0.29182 & & & \\
\hline IPB & -0.15201 & 0.87918 & SSZL & 1.00562 & 0.31460 & PX-50 & 0.61271 & 0.54007 \\
\hline KOMB & 0.57391 & 0.56603 & SVDL & 1.00600 & 0.31442 & PX D & -0.65646 & 0.51153 \\
\hline
\end{tabular}

Based on the above, any abnormally profitable investment strategy on the Czech market may exploit short-term dependences; no systemic opportunities should exist in terms of weeks or months. Such strategies can be effectively realized by professional in-

6 Hanousek, Němeček (1997, 1998), Němeček (1998), Filáček, Kapička, Vošvrda (1998), Trešl (1999), Rockinger, Urga (1999), Chun (2000), Podpiera (2001), Hájek (2002), Gilmore, McManus (2003), Worthington, Higgs (2003).

7 Outcomes of the weekly-data analysis are not displayed and can be provided by the author on request. Overall, neither the pure random walk nor systematic departures from the random walk can be observed; interpretation of the results is thus ambiguous. Moreover, outputs in case of the market indices are sensitive to the choice of the decisive day for calculation of the weekly return. While Friday's returns are linearly dependent, Tuesday's returns behave randomly for both the PX-50 and PXD index.

8 Some articles contradict the prevailing evidence; see Hanousek, Němeček (1999), Vošvrda, Žikeš (2004) and Horská (2005). 
vestors, brokerage houses and especially market makers that have exclusive and prompt access to new information and the trading system. Abnormally profitable opportunities for retail investors with higher transaction costs and longer reaction time are unlikely to appear. Autocorrelation coefficients are mostly positive; investment strategies should therefore anticipate successive daily price changes of the same sign.

\subsection{Non-synchronous Trading}

Empirical results are scrutinized and, possibly, adjusted to reflect the non-trading effects before final conclusions are formulated, especially as far as the daily-data analysis is concerned. Effects of non-trading emerge when the data collection frequency exceeds the empirical frequency of trading. An assumption of the evenly distributed price changes, e.g. the daily period, may lead to the spurious return predictability although real price changes remain independent. Such predictability does not allow, however, superior profitable trading. Spurious autocorrelations would be positive in case of portfolios or indices and negative in case of individual stocks. ${ }^{9}$

A model of non-synchronous trading by Lo, MacKinlay (1990) is employed to describe return autocorrelations generated by non-trading. The model assumes continuously compounded virtual returns $r_{i t}$ of a stock $i$ in a period $t$. On the efficient market, they represent changes in the stock fundamental value and they are independent in any period. They equal to reported (observed) price changes $r_{i t}{ }^{0}, r_{i t}{ }^{0}=\log \left(p_{i t} / p_{i t-1}\right)$, as far as the stock is sufficiently liquid. For a portfolio of $N$ stocks it holds:

$$
r_{i t}^{0}=\sum_{k=0}^{k t} r_{i t-k}, \quad i=1, \ldots, N
$$

The duration of non-trading $k_{t}$, i.e. the number of subsequent periods (days) that $i$ has not traded, is the key parameter in the above-mentioned sum of virtual returns (whether the stock trades or not is independent of any random variables in the model). It may be expressed:

$$
k_{t} \equiv \sum_{k=0}^{\infty}\left\{\prod_{j=1}^{k} \delta_{i t-j}\right\}, \text { where } \delta_{i t}=\left\{\begin{array}{cl}
1(\text { no trade }) & \text { with probability } \pi_{i} \\
0(\text { trade }) & \text { with probability } 1-\pi_{i}
\end{array}\right.
$$

The dummy parameter $\delta_{i t}$ takes on the unity if a stock $i$ does not trade in a period $t$ and is zero otherwise. Defining variable $\pi_{i t}$ as probability that a stock $i$ does not trade in a period $t$, it holds:

$$
E\left[k_{t}\right]=\pi_{i} /\left(1-\pi_{i}\right), \quad \operatorname{Var}\left[k_{t}\right]=\pi_{i} /\left(1-\pi_{i}\right)^{2}
$$

Assuming non-zero expected (required) mean of returns $\mathrm{E}\left[r_{i t}{ }^{0}\right]=\mu_{i}, \mu_{i} \neq 0$, non-synchronous trading causes negative return autocorrelation in the individual stock time series. Autocorrelations are geometrically decreasing with increasing legs:

9 For more details see e.g. Lo, MacKinlay (1990). 


$$
\operatorname{Corr}\left[r_{i t}^{0}, r_{i t-k}^{0}\right]=-\mu_{i}^{2} \pi_{i}^{k} /\left(\sigma_{i}^{2}+\frac{2 \pi_{i}}{1-\pi_{i}} \mu_{i}^{2}\right), \quad k>0
$$

where $\sigma_{i}^{2} \equiv \operatorname{Var}\left[r_{i t}\right]$. In case of indices, the spurious autocorrelation formula is applicable solely to portfolios $\lambda$ of stocks with identical probability of non-trading $\pi_{\lambda}$, and it holds:

$$
\operatorname{Corr}\left[r_{\lambda t}^{0}, r_{\lambda t-k}^{0}\right]^{a}=\pi_{\lambda}^{k}, \quad k \geq 0, \text { where } r_{\lambda t}^{0} \approx N_{\lambda}^{-1} \sum_{i \in \lambda} r_{i t}^{0}
$$

However, Lo, MacKinlay do not elaborate on distribution characteristics of the above-mentioned variables and they cannot be therefore used for explicit quantitative analysis. In spate of this, a part of autocorrelation that may indicate market inefficiency can be reasonably estimated by comparing empirically measured autocorrelations and spurious autocorrelations. However, indices in the Central European area commonly consist of stocks with the heterogeneous empirical probability of non-trading (see Table 5 for the PX-50 index). Spurious autocorrelation estimates are then inapplicable.

Table 5

Non-trading Probability, CZ, 1995-2005

\begin{tabular}{|l|r|r|r|l|r|r|r|l|r|r|r|}
\hline & 1 Day & 1 Week & 1 Month & & 1 Day & 1 Week & 1 Month & & 1 Day & 1 Week & 1 Month \\
\hline CBJ & $39.849 \%$ & $10.600 \%$ & $1.575 \%$ & PARM & $51.511 \%$ & $29.440 \%$ & $9.346 \%$ & TABAK & $6.702 \%$ & $0.768 \%$ & $0.000 \%$ \\
\hline CEZ & $5.654 \%$ & $0.524 \%$ & $0.000 \%$ & RBAG & $3.673 \%$ & $0.000 \%$ & $0.000 \%$ & UNIP & $3.961 \%$ & $0.046 \%$ & $0.000 \%$ \\
\hline CS & $6.032 \%$ & $0.889 \%$ & $0.000 \%$ & SKUH & $35.690 \%$ & $9.639 \%$ & $0.000 \%$ & & & & \\
\hline CSRD & $7.775 \%$ & $0.808 \%$ & $0.000 \%$ & SPTT & $5.632 \%$ & $0.567 \%$ & $0.000 \%$ & MAX & $60.970 \%$ & $36.480 \%$ & $17.500 \%$ \\
\hline IAPS & $17.362 \%$ & $6.177 \%$ & $0.000 \%$ & SSZL & $60.970 \%$ & $30.524 \%$ & $9.322 \%$ & MIN & $3.673 \%$ & $0.000 \%$ & $0.000 \%$ \\
\hline IPB & $8.989 \%$ & $2.177 \%$ & $0.000 \%$ & SVDL & $43.807 \%$ & $18.014 \%$ & $3.333 \%$ & AVG & $25.708 \%$ & $11.222 \%$ & $3.066 \%$ \\
\hline KOMB & $4.782 \%$ & $0.489 \%$ & $0.000 \%$ & SVEG & $54.514 \%$ & $32.170 \%$ & $9.917 \%$ & $\begin{array}{l}\text { ST. } \\
\text { DEV. }\end{array}$ & $22.403 \%$ & $13.256 \%$ & $5.092 \%$ \\
\hline OKD & $47.228 \%$ & $22.683 \%$ & $4.202 \%$ & SVEN & $58.610 \%$ & $36.480 \%$ & $17.500 \%$ & & & & \\
\hline
\end{tabular}

Estimated values of negative first-leg return autocorrelations caused by non-trading are largely insignificant. The average value of -0.0003 in case of weekly returns (maximum -0.0023) has virtually no impact on the result interpretation, less so values for daily and monthly returns (maximum -0.0014 and -0.0015). Moreover, the induced autocorrelations geometrically decay with higher legs. The non-trading effects in time series of individual stocks may be therefore omitted without a significant reduction in robustness of the conclusions.

The Lo, MacKinlay model of non-synchronous trading cannot be effectively applied in case of the PX-50 index given the stocks' heterogeneous non-trading probability. While the average probability reaches almost $26 \%$, standard deviation approaches 22 percentage points. Therefore, it cannot be ruled out that daily non-trading causes significant spurious positive autocorrelations and influences thus the result interpretation. The impact of non-trading may be further enhanced by the fact that periods of both trading and non-trading are clustered. On the other hand, the PX-D index behaves as a rather homogenous portfolio; the average non-trading probability reaches $4.052 \%$ with standard deviation of 0.701 percentage points. The non-trading effects are 
unimportant to the PX-D result interpretation as the empirical daily-return autocorrelations are positive and statistically insignificant (see Table 1).

\subsection{Relative Efficiency}

A vast majority of available studies of the market efficiency in the Central European region has analysed behaviour of stock market indices. However, the relative efficiency test and more complex analysis require time series of individual stock to be employed. ${ }^{10}$

The concept of relative efficiency has been discussed by Lo, MacKinlay (1999) who compared the approach to the traditional test of "absolute" efficiency (i.e. the test of the model-like behaviour). Its advantages are demonstrated employing the analogy with engine efficiency. The absolute efficiency approach is applicable solely under the ideal theoretical assumptions and remains unfeasible in practice. As far as no perfect engines and markets exist, the relative efficiency analysis should deliver additional information up to those brought by the econometric tests of the model-like behaviour.

The above-stated results of the econometric analysis are therefore further compared with the results of the same analysis applied to the most developed capital markets. The New York Stock Exchange (NYSE) and German and Netherlands exchanges are considered as benchmarks. They are assumed to be the most efficient markets worldwide and in the European context.

The following paragraphs address whether significant dependences appear on the Czech market as frequently as on the developed markets. More specifically, it is analysed whether the variance ratio test indicates a significantly higher frequency of linear dependences. Given the different number of index members, the hypothesis of the equal relative frequencies $\pi_{i}$ is tested (at the $5 \%$ confidential level). The Fisher factorial one-sided test for small samples is applied to statistically test relative frequencies for every separate $q$ of the variance ratio, with hypothesis $\mathrm{H}_{0}: \pi_{1}=\pi_{2}$ and $\mathrm{H}_{1}: \pi_{1}>\pi_{2}{ }^{11}$

Assuming that the hypothesis holds for a given number of stocks in the Czech and foreign index $\left(n_{1}\right.$ and $\left.n_{2}\right)$, numbers of statistical significant values of the test statistic (variance ratio) on both markets $\left(m_{1}\right.$ and $\left.m_{2}\right)$ are independent random variables with binominal distribution $\operatorname{Bi}\left(n_{1}, \pi\right)$ and $\operatorname{Bi}\left(n_{2}, \pi\right)$, where $\pi_{1}=\pi_{2}=\pi$. The hypothesis is refused if the following expression holds for the searched probability $P$ :

$$
\begin{gathered}
\sum_{t=m_{1}}^{m_{+}+m_{2}} P\left(t, m_{1}+m_{2}-t \mid m_{1}+m_{2}\right) \leq \alpha, \text { where } \\
P\left(t, m_{1}+m_{2}-t \mid m_{1}+m_{2}\right)=\frac{n_{1} ! n_{2} !\left(m_{1}+m_{2}\right) !\left(n_{1}+n_{1}-m_{1}-m_{2}\right) !}{\left(n_{1}+n_{2}\right) ! t !\left(n_{1}-t\right) !\left(m_{1}+m_{2}-t\right) !\left(n_{2}-m_{2}-m_{1}+t\right) !}
\end{gathered}
$$

where $t$ is a number of the frequency combinations in the four-cell table (given by $n_{1}, n_{2}$, $m_{1}$ and $\left.m_{2}\right)$ and where $\alpha$ is a selected confidence level (0.05).

10 As exceptions, Němeček (1998) analysed Czech individual stocks, Scheicher (1999), Wheeler et al. (2002) and Zgaljic (2004) focused on Polish stocks and Huber (1995) analysed Austrian stocks.

11 See e.g. Hebák (1995) or Hebák et al. (2004). 
The Fisher factorial test, however, assumes samples of up to twenty values, which is not always fulfilled (both DJIA and DAX have 30 members). The two-sided test for large samples is therefore applied, with hypothesis $\mathrm{H}_{0}: \pi_{1}=\pi_{2}$ and $\mathrm{H}_{1}: \pi_{1} \neq \pi_{2}$. Dependences are also compared aggregately for all compounded periods $q, q=2, \ldots, 12$. The test statistic $U$ has asymptotically normal distribution:

$$
U=\frac{P_{1}-P_{2}}{\sqrt{\bar{P}(1-\bar{P})\left(n_{1}^{-1}+n_{2}^{-1}\right)}}, \text { where }
$$

$P_{k}$ are sample relative frequencies, $P_{k}=m_{k} / n_{k}$ and $\bar{P}$ is the average sample relative frequency given by $\left(m_{1}+m_{2}\right) /\left(n_{1}+n_{2}\right)$.

The benchmark is firstly established. Table 6 shows both absolute and relative frequencies of significant linear dependencies in time series of daily returns according to the variance ratio test on the US, German and Netherlands markets. Significant autocorrelations are rather common over all legs, especially on the US market.

Table 6

Frequency of Significant Dependences, VR Test, Foreign Markets, Daily Returns, 1995-2005

\begin{tabular}{|c|c|c|c|c|c|c|c|c|c|c|c|c|}
\hline & $\mathbf{N}$ & $q=2$ & $q=3$ & $q=4$ & $q=5$ & $q=6$ & $q=7$ & $q=8$ & $q=9$ & $q=10$ & $q=11$ & $q=12$ \\
\hline \multirow{2}{*}{ USA } & \multirow{2}{*}{30} & 2 & 3 & 4 & 6 & 6 & 8 & 9 & 11 & 11 & 12 & 12 \\
\hline & & $7 \%$ & $10 \%$ & $13 \%$ & $20 \%$ & $20 \%$ & $27 \%$ & $30 \%$ & $37 \%$ & $37 \%$ & $40 \%$ & $40 \%$ \\
\hline \multirow{2}{*}{ GER } & \multirow{2}{*}{30} & 2 & 3 & 5 & 5 & 5 & 5 & 6 & 5 & 5 & 5 & 5 \\
\hline & & $7 \%$ & $10 \%$ & $17 \%$ & $17 \%$ & $17 \%$ & $17 \%$ & $20 \%$ & $17 \%$ & $17 \%$ & $17 \%$ & $17 \%$ \\
\hline \multirow{2}{*}{ NED } & \multirow{2}{*}{20} & 3 & 4 & 2 & 0 & 0 & 0 & 1 & 2 & 2 & 2 & 2 \\
\hline & & $15 \%$ & $20 \%$ & $10 \%$ & $0 \%$ & $0 \%$ & $0 \%$ & $5 \%$ & $10 \%$ & $10 \%$ & $10 \%$ & $10 \%$ \\
\hline
\end{tabular}

Secondly, the Czech and developed market is compared. A review of significant autocorrelation frequencies on the Czech market for the first eleven compounded periods $q$ is provided in Appendix 2. Although significant autocorrelations in time series of daily returns are evident on both markets, the Fisher factorial one-sided test of the equal frequencies for small samples clearly proves in Table 7 that they are systematically more frequent on the Czech market. The two-sided test for large samples, which was applied separately to every compounded period $q$, delivers comparable results (not displayed). When used aggregately for all compounded periods $q$, the test confirms different characteristics of the markets as well.

Table 7

Fisher Factorial Test of the Equal Frequencies of Significant Dependences, Daily Returns, 1995-2005

\begin{tabular}{|l|c|c|c|c|c|c|c|c|c|c|c|}
\hline & $\mathbf{q}=\mathbf{2}$ & $\mathbf{q}=\mathbf{3}$ & $\mathbf{q}=\mathbf{4}$ & $\mathbf{q}=\mathbf{5}$ & $\mathbf{q}=\mathbf{6}$ & $\mathbf{q}=\mathbf{7}$ & $\mathbf{q}=\mathbf{8}$ & $\mathbf{q}=\mathbf{9}$ & $\mathbf{q}=\mathbf{1 0}$ & $\mathbf{q}=\mathbf{1 1}$ & $\mathbf{q}=\mathbf{1 2}$ \\
\hline USA & $0.000 *$ & $0.000 *$ & $0.000 *$ & $0.000 *$ & $0.005 *$ & $0.020 *$ & $0.035 *$ & 0.164 & 0.164 & 0.353 & 0.353 \\
\hline GER & $0.000 *$ & $0.000 *$ & $0.000 *$ & $0.000 *$ & $0.002 *$ & $0.002 *$ & $0.005 *$ & $0.007 *$ & $0.007 *$ & $0.017 *$ & $0.017 *$ \\
\hline NED & $0.001 *$ & $0.002 *$ & $0.000 *$ & $0.000 *$ & $0.000 *$ & $0.000 *$ & $0.000 *$ & $0.003 *$ & $0.003 *$ & $0.008 *$ & $0.008 *$ \\
\hline
\end{tabular}

* The string indicates significantly different frequencies. 
The above mentioned methodology is further applied to the monthly data. Contrary to the daily return analysis, significant linear dependencies of monthly returns are only exceptional on the developed markets. It is evident from Table 8 that the Czech markets has comparable characteristics for $q<7$, which is in line with the results shown in Table 4. However, rather high frequencies of significant autocorrelations (up to five stocks, see Appendix 2) are indicated by the Fisher factorial test if more than six periods $q$ are compounded. An intuitive explanation of the phenomenon is not obvious, though.

Table 8

Fisher Factorial Test of the Equal Frequencies of Significant Dependences, Monthly Returns, 1995-2005

\begin{tabular}{|l|l|l|l|l|l|l|l|l|l|l|l|}
\hline & $\mathbf{q}=\mathbf{2}$ & $\mathbf{q = 3}$ & $\mathbf{q}=\mathbf{4}$ & $\mathbf{q}=\mathbf{5}$ & $\mathbf{q}=\mathbf{6}$ & $\mathbf{q}=\mathbf{7}$ & $\mathbf{q}=\mathbf{8}$ & $\mathbf{q}=\mathbf{9}$ & $\mathbf{q}=\mathbf{1 0}$ & $\mathbf{q = 1 1}$ & $\mathbf{q}=\mathbf{1 2}$ \\
\hline USA & 0.375 & 1.000 & 0.375 & 0.375 & 0.375 & $0.047^{*}$ & $0.016^{*}$ & $0.016^{*}$ & $0.005^{*}$ & $0.005^{*}$ & $0.022^{*}$ \\
\hline GER & 0.765 & 1.000 & 0.375 & 0.375 & 0.375 & $0.047^{*}$ & $0.016^{*}$ & $0.016^{*}$ & $0.005^{*}$ & $0.005^{*}$ & $0.005^{*}$ \\
\hline NED & 0.730 & 1.000 & 0.474 & 0.730 & 0.474 & 0.097 & $0.041^{*}$ & $0.041 *$ & $0.017 *$ & $0.017^{*}$ & $0.017^{*}$ \\
\hline
\end{tabular}

* The string indicates significantly unequal frequencies

To sum up, significant linear dependencies in daily stock returns are substantially more frequent on the Czech market than on the developed markets. Although the weekly data analysis brings more enthusiasm and finds both markets comparable, the above-mentioned evidence is sufficient to conclude that the empirical results contradict the hypothesis and the Czech market seems relatively (weak-form) inefficient.

\section{Conclusions}

The article addresses the efficient market hypothesis - its weak form - in the Czech Republic in 1995-2005. Based on the empirical analysis and relevant available studies, major factors that may influence the results are analysed and, possibly, generalized. The article complexity helps to interpret several sources of discrepancies in the up-to-now studies.

The weak form of the EMH cannot be validated on the Czech stock market. Daily price changes of both individual stocks and indices are systematically linearly dependent and the dependencies cannot be explained by the non-trading factor. Frequencies of the significant return autocorrelations in time series of the analysed Czech stocks have been compared with frequencies that occur on the most developed global markets, such as the American NYSE or the German and Netherlands stock exchanges. The analysis has proved that the Czech market is relatively less effective than the developed markets. Historical information on stock prices or indices may have economically significant values.

Further particular conclusions can be formulated. Firstly, the time-variable variance is typical for time series of the Czech index and stock price changes. The heteroskedasticity-consistent methodology must be therefore applied to avoid significant biases while testing the Central European market efficiency. Secondly, a choice of the data frequency is crucial. Both daily stock returns and daily index returns are significantly linearly dependent, which does not support the EMH. On the other hand, the Czech stock market seems weak-from efficient when the lower frequency data (weekly and, partially, monthly) are employed. Any investment strategy must therefore 
exploit short-term dependences to become abnormally profitable. Moreover, while the overall probability of non-trading is rather high on the Czech market, it has no material impact on the result interpretation in case of the PX-D index and individual stocks. The applied non-synchronous trading model however fails to correctly estimate spurious autocorrelations of the PX-50 index returns with a possible impact on the result interpretation in this case.

Moreover, the importance of a sufficient time span for the EMH testing is emphasized. The hypothesis claims that a market is inefficient if an information set can be used to reach the above-average profits in the long term. The sufficient length is a precondition for time series to contain information on the systemic behaviour of the market while ignoring interim variations. An analysis of shorter periods (several years) may deliver irrelevant outputs. For example, if the eleven-year time series of the Czech stock returns are halved and the results for two successive five-year sub-periods are compared, one might conclude that the Czech market became more efficient. However, if the same analysis is applied analogically to the NYSE daily returns, every fifths stock is linearly dependent in 1995-2000 while a single exception from the random walk can be found in the second sub-period. NYSE - the most effective market worldwide - hardly became (weak-form) efficient only in the last several years, though. The five-year time span clearly remains insufficient and no robust conclusions may be formulated about the efficiency development. Time series of the maximum available length should be applied when analyzing the Central European market efficiency.

\section{References}

Diviš, K., Teplý, P. (2005), "Informační efektivnost burzovních trhů ve střední Evropě." Finance a úvěr, 55 (9-10), pp. 471-482.

Dockery, E., Vergari, F. (1997), "Testing the Random Walk Hypothesis: Evidence for the Budapest Stock Exchange." Applied Economics Letters, 4, pp. 627-629.

Engle, R. F. (1982), "Autoregressive Conditional Heteroskedasticity with Estimates of the Variance of UK Inflation." Econometrica, 50, pp. 987-1008.

Fama, E. (1965), "The Behavior of Stock Market Prices." Journal of Business, 38, pp. 34-105.

Fama, E. (1970), "Efficient Capital Markets: A Review of Theory and Empirical Work." Journal of Finance, 25, pp. 383-417.

Fama, E. (1997), "Market Efficiency, Long-Term Returns and Behavioural Finance." CRSP Working Paper, No. 448, University of Chicago.

Filáček, J., Kapička, M., Vošvrda, M. (1998), "Testování hypotézy efektivního trhu na BCPP." Finance a úvěr, 48 (9), pp. 554-566.

Filer, R.K., Hanousek, J. (1996), "The Extent of Efficiency in Central European Equity Markets." CERGE-EI Working Paper Series, No. 104, Prague, November 1996.

Filer, R.K., Hanousek, J. (1999), "The Extent of Efficiency in Central European Equity Markets," in Helmenstein, C., ed., Capital Markets in Transition Economies. Cheltenham, UK : Edward Edgar, pp. 392-416.

Gilmore, C.G., McManus, G.M. (2003), "Random-Walk and Efficiency Tests of Central European Equity Markets." Managerial Finance, 29 (4), pp. 42-61.

Gunduz, L., Hatemi, J.A. (2005), "Stock Price-Volume Relation in East European Stock Markets." Emerging Markets Finance and Trade, 41 (1), pp. 29-45.

Hájek, J. (2002), "Slabá forma efektivnosti českého akciového trhu." Politická ekonomie, 50 (3), pp. 377-389.

Hanousek, J., Němeček, L. (1997), "Co-movements and Interactions between Segments of Parallel Markets: The Case of the Czech Republic." CERGE-EI Working Paper Series, No. 122, Prague, December 1997. 
Hanousek, J., Němeček, L. (1998), "Mispricing and Lasting Arbitrage between Parallel Markets in the Czech Republic." CERGE-EI Working Paper Series, No. 136, Prague, December 1998.

Hanousek, J., Němeček, L. (1999), "Czech Parallel Capital Markets: Discrepancies and Inefficiencies." CERGE-EI Discussion Papers, Prague, February 1999.

Hebák, P. (1995), Testování statistických hypotéz. Praha : VŠE.

Hebák, P., Bílková, D., Svobodová, A. (2004), Praktikum k výuce matematické statistiky II: Testování hypotéz. Praha : VŠE.

Horská, H. (2005), "Český akciový trh - jeho efektivnost a makroekonomické souvislosti." Finance a úvěr, 55 (5-6), pp. 283-301.

Huber, P. (1995), "Random Walks in Stock Exchange Prices and the Vienna Stock Exchange." Reihe Ekonomie Economic Series, No. 2, Vienna, January 1995.

Chun, R.M. (2000), "Compensation Vouchers and Equity Markets: Evidence from Hungary." Journal of Banking \& Finance, 24, pp. 1155-1178.

Lo, A.W., MacKinlay, A.C. (1988), "Stock Prices Do Not Follow Random Walks: Evidence from a Simple Specification Test." Review of Financial Studies, 1, pp. 41-66.

Lo, A.W., MacKinlay, A.C. (1989), "The Size and Power of the Variance Ratio Test in Finite Samples: A Monte Carlo Investigation." Journal of Econometrics, 40, pp. 203-238.

Lo, A.W., MacKinlay, A.C. (1990), "An Econometric Analysis of Nonsynchronous Trading." Journal of Econometrics, 45, pp. 181-212.

Lo, A.W., MacKinlay, A.C. (1999), A Non-random Walk down Wall Street. Princeton : Princeton University Press.

Malkiel, B. G. (2003), "The Efficient Market Hypothesis and Its Critics." Journal of Economic Perspectives, 17 (1), pp. 59-82.

Němeček, L. (1998), "Capital Market in the Czech Republic: Birth and the First Steps" (Doctoral Thesis). CERGE, Charles University of Prague.

Nivet, J.-F. (1997), "Stock Markets in Transition: the Warsaw Experiment." Economics of Transition, 5, pp. 171-183.

Podpiera, R. (2001), "International Cross-Listing: The Effects of Market Fragmentation and Information Flows." CERGE-EI Working Paper Series, No. 173, Prague, April 2001.

Roberts, H. (1967), "Statistical Versus Clinical Prediction of the Stock Market." CRSP University of Chicago, May 1967.

Rockinger, M., Urga, G. (2001), "A Time-Varying Parameter Model to Test for Predictability and Integration in the Stock Markets of Transition Economies." Journal of Business \& Economic Statistics, 19 (1), pp. 73-84.

Roll, R. (1994), "What Every CEO Should Know About Scientific Progress in Economics: What is Known and What Remains to be Resolved." Financial Management, 23, pp. 69-75.

Samuelson, P. (1965), "Proof That Properly Anticipated Prices Fluctuate Randomly." Industrial Management Review, 6, pp. 41-49.

Scheicher, M. (1999), "Modeling Polish Stock Returns." in Helmenstein, C., ed., Capital Markets in Transition Economies. Cheltenham, UK : Edward Edgar, pp. 417-437.

Schotman, P.C., Zalewska, A. (2004), "How Far Do International Investment Opportunities Extend to the Markets of the Post-communist Countries? Testing for Predictability and Integration." EMG/ESRC Workshop - EBRD Paper, September 2004.

Trešl, J. (1999), "Analýza sektorových indexů na pražské burze cenných papírů." Politická ekonomie, 1, pp. 27-39.

Vošvrda, M., Žikeš, F. (2004), "An application of the GARCH-t Model on Central European Stock Returns." Prague Economic Papers, 1, pp. 26-39.

Wheeler, F.P., Neale, B., Kowalski, T., Letza, S.R. (2002), "The Efficiency of the Warsaw Stock Exchange: the First Few Years 1991-1996." The Poznan University of Economics Review, 2 (2), pp. 37-58.

Worthington, A.C., Higgs, H. (2003), "Weak-form Market Efficiency in European Emerging and Developed Stock Markets." Queensland University of Technology Discussion Paper, No. 159, September 2003.

Zgaljic, D. (2004), "Capital Market Efficiency in Poland: An Analysis of Weak-form Efficiency on the Warsaw Stock Exchange" (Master Thesis). Massachusetts, USA : Tufts University.

Žikeš, F. (2003), "The Predictability of Asset Returns: An Empirical Analysis of Central-European Stock Markets" (Master Thesis). Charles University of Prague (IES). 


\section{Appendix 1 \\ List of Analysed Stocks}

\begin{tabular}{|l|l|l|l|}
\hline \multicolumn{2}{|l|}{ Czech Republic } & \multicolumn{2}{l|}{ Netherlands } \\
\hline CBJ & Česká pojiš ovna & AABA & ABN Amro \\
\hline CEZ & ČEZ & AGN & Aegon \\
\hline CS & Česká spořitelna & AH & Ahold \\
\hline CSRD & České radiokomunikace & AKZA & Akzo Nobel \\
\hline IAPS & IPS Skanska & ASML & ASML Holding \\
\hline IPB & IPB & BUHR & Buhrmann \\
\hline KOMB & Komerční banka & DSM & DSM \\
\hline OKD & OKD & FORA & Fortis \\
\hline PARM & Paramo & GTN & Getronics \\
\hline RBAG & Erste Bank & HEIA & Heineken \\
\hline SKUH & Sokolovská uhelná & HGM & Hagemeyer \\
\hline SPTT & Český Telecom & INGA & ING Groep \\
\hline SSZL & SSŽ & KPN & Royal KPN \\
\hline SVDL & Severočeské doly & NUM & Royal Numico \\
\hline SVEG & Severočeská energetika & PHIA & Philips Electronics \\
\hline SVEN & Severomoravská energetika & RDA & Royal Ducht Petroleum \\
\hline TABAK & Philip Morris ČR & REN & Reed Elsevier \\
\hline UNIP & Unipetrol & SBMO & IHC Caland \\
\hline & & TNT & TPG \\
\hline & & UNA & Unilever \\
\hline
\end{tabular}

\begin{tabular}{|l|l|l|l|}
\hline \multicolumn{2}{|l|}{ United States } & & Germany \\
\hline AA & Alcoa & ADS & Adidas-Salomon \\
\hline AIG & AIG & ALT & Allianz \\
\hline AXP & American Express & ALV & Altana \\
\hline BA & Boeing & BAS & BASF \\
\hline CAT & Caterpillar & BAY & Bayer \\
\hline CITI & Citigroup & BMW & BMW \\
\hline DD & Du Pont & CBK & Commerzbank \\
\hline DIS & Walt Disney & CONN & Continental \\
\hline GE & General Electric & DB1 & Deutsche Boerse \\
\hline GM & General Motors & DBK & Deutsche Bank \\
\hline HD & Home Depot & DCX & DaimlerChrysler \\
\hline HON & Honeywell Int. & DPW & Deutsche Post \\
\hline HPQ & Hewlett-Packard & DTE & Deutsche Telecom \\
\hline IBM & IBM & EOA & E.ON \\
\hline INTC & Intel Corp & FME & Fresenius Medical Care \\
\hline JNJ & Johnson \& Johnson & HEN3 & Henkel \\
\hline JPM & JPMorgan Chase & HVM & Bayerische Hypo-Vereinsbank \\
\hline KO & Coca-Cola & IFX & Infineon \\
\hline MCD & McDonald's & LHA & Deutsche Lufthansa \\
\hline MMM & 3M & LIN & Linde \\
\hline MO & Altria Group & MAN & MAN \\
\hline MRK & Merck & MEO & Metro \\
\hline MSFT & Microsoft & MUV2 & Muenchener Re \\
\hline PFE & Pfizer & RWE & RWE \\
\hline PG & Procter \& Gamble & SAP & SAP \\
\hline T & SBC Communications & SCH & Schering \\
\hline UTX & United Technologies & SIE & Siemens \\
\hline VZ & Verizon Communications & TKA & ThyssenKrupp \\
\hline WMT & Wal-Mart Stores & TUI1 & TUI \\
\hline XOM & Exxon Mobil & VOW & Volkswagen \\
\hline & & & \\
\hline
\end{tabular}


Appendix 2

Variance Ratio Test, $q \in(2,12), C Z$, Daily and Monthly Returns, 1995-2005

\section{Daily}

\begin{tabular}{|c|c|c|c|c|c|c|c|c|c|c|c|}
\hline $\mathbf{C Z}$ & $\mathbf{Z}_{2}{ }^{*}$ & $\mathbf{Z}_{3}{ }^{*}$ & $\mathbf{Z}_{4}$ * & $\mathbf{Z}_{5}$ * & $\mathbf{Z}_{6}$ * & $\mathbf{Z}_{7}$ * & $\mathbf{Z}_{8}$ * & $\mathbf{Z}_{9}$ * & $Z_{10}$ * & $Z_{11}$ * & $Z_{12}$ * \\
\hline PX50 & 4999* & $8019 *$ & $6569 *$ & $.6699 *$ & $.4984 *$ & $4.3716^{*}$ & $4.1970 *$ & $4.0188^{*}$ & $3.9391 *$ & & $3.9789 *$ \\
\hline MAX & & & & & 9.0234 & 8.7515 & 8.5649 & & 12 & 7.9132 & 7.8100 \\
\hline MIN & 50 & 710 & 00 & -0.2610 & -0.4668 & -0.9602 & -1.2711 & -1.4727 & -1 . & -1.6897 & -1.6741 \\
\hline MEDIAN & 09 & 3604 & 64 & 3.2 & 3.0 & 2.9 & 2.7 & 2. & 2. & 2. & 2.3261 \\
\hline REFUSALS & $12 / 18$ & $13 / 18$ & $13 / 18$ & $13 / 18$ & $11 / 18$ & $11 / 18$ & $11 / 18$ & $10 / 18$ & $10 / 18$ & $9 / 18$ & $9 / 18$ \\
\hline
\end{tabular}

\section{Monthly}

\begin{tabular}{|l|c|c|c|c|c|c|c|c|c|c|c|}
\hline \multicolumn{1}{|c|}{$\mathbf{C Z}$} & $\mathbf{Z}^{2 *}$ & $\mathbf{Z}_{3}{ }^{*}$ & $\mathbf{Z}_{4}{ }^{*}$ & $\mathbf{Z}_{5}{ }^{*}$ & $\mathbf{Z}_{\mathbf{6}}{ }^{*}$ & $\mathbf{Z}_{7}{ }^{*}$ & $\mathbf{Z}_{8}{ }^{*}$ & $\mathbf{Z}_{9}{ }^{*}$ & $\mathbf{Z}_{\mathbf{1 0}}{ }^{*}$ & $\mathbf{Z}_{11}{ }^{*}$ & $\mathbf{Z}_{12}{ }^{*}$ \\
\hline PX50 & 0.6127 & 0.1970 & 0.0080 & -0.1779 & -0.1516 & -0.0056 & 0.1755 & 0.3267 & 0.4446 & 0.6463 & 0.7896 \\
\hline MAX & 2.1573 & 1.6755 & 1.9693 & 2.2723 & 2.4374 & 2.4987 & 2.4812 & 2.5447 & 2.6975 & 2.8492 & 2.9680 \\
\hline MIN & -1.1464 & -1.1098 & -1.1464 & -1.1787 & -1.2320 & -1.1075 & -1.0074 & -1.0195 & -0.9580 & -1.1145 & -1.2454 \\
\hline MEDIAN & 0.5196 & 0.5412 & 0.5136 & 0.5851 & 0.6292 & 0.7143 & 0.8143 & 0.9113 & 1.0018 & 1.0849 & 1.1549 \\
\hline REFUSALS & $1 / 18$ & $0 / 18$ & $1 / 18$ & $1 / 18$ & $1 / 18$ & $3 / 18$ & $4 / 18$ & $4 / 18$ & $5 / 18$ & $5 / 18$ & $5 / 18$ \\
\hline
\end{tabular}

Note: In both tables, the first row shows the variance-ratio test statistic $Z_{2}^{*}$ (for $\left.q=2, \ldots, 12\right)$ for the $P X-50$ index (the string indicates statistic significance); the following rows show maximal, minimal and median values of the test statistic for individual stocks. The final row contents the absolute frequency of significantly dependent stock returns out of the eighteen analysed time series. 